\title{
Archaea in Food Microbiology: Are They Really Possible Threat or Not?
}

\author{
Mostafa Essam Ahmed Mostafa Eissa* \\ Quality Unit, HIKMA Pharma, Egypt
}

*Corresponding author: Mostafa Essam Ahmed Mostafa Eissa, Quality Unit, HIKMA Pharma, 2nd Industrial Zone, Plot no. 1, Giza, Egypt

Submission: September 15, 2017; Published: November 14, 2017

\begin{abstract}
In the world of continually growing populations of health compromised individuals, there is an expanding list of pathogenic microorganisms. The list normally includes mainly bacteria, fungi, viruses and protozoa. While the discovery of domain Archaea is considered relatively recent, its biological interaction with human life is still mysterious at different perspectives. This domain is highly distributed globally, even in the harsh environmental conditions, where the possibility of life form existence was excluded. The difficulty of culturing many of Archaeal organisms using conventional culture media is a true barrier for any detection and/or studying of these entities. Only when new bimolecular technologies came into play, some of the ambiguity of these single-celled organisms has begun to resolve. Accordingly, many of Archaeal species may pass the quality control tests undetected to the final consumers. No solidly established data are available till now on our hand about spoilage of food products either preserved or not on storage by Archaea. Moreover, all studies about probable link between certain disease conditions and the presence of Archean are speculating and no true relation was established till now. Thus, the disregard of these microorganisms-especially those on, inside, very close to the human body and the surrounding environment-as potential threat to our life may be a haste discussion when no scientifically rational evidence are available till now. Extensive studies are required to solve this dilemma in a timely manner.
\end{abstract}

Keywords: Archaea; Culture media; Phylogenetic tree; Molecular techniques; Ancestral organism; Prokaryotes; Eukarya; Statin; Haloarchaea; Methanoarchaea; Methanobrevibacter smithii

Abbreviations: QC: Quality Control; rRNA: ribosomal Ribonucleic Acid; VBNC: Viable but not Culturable

\section{Introduction}

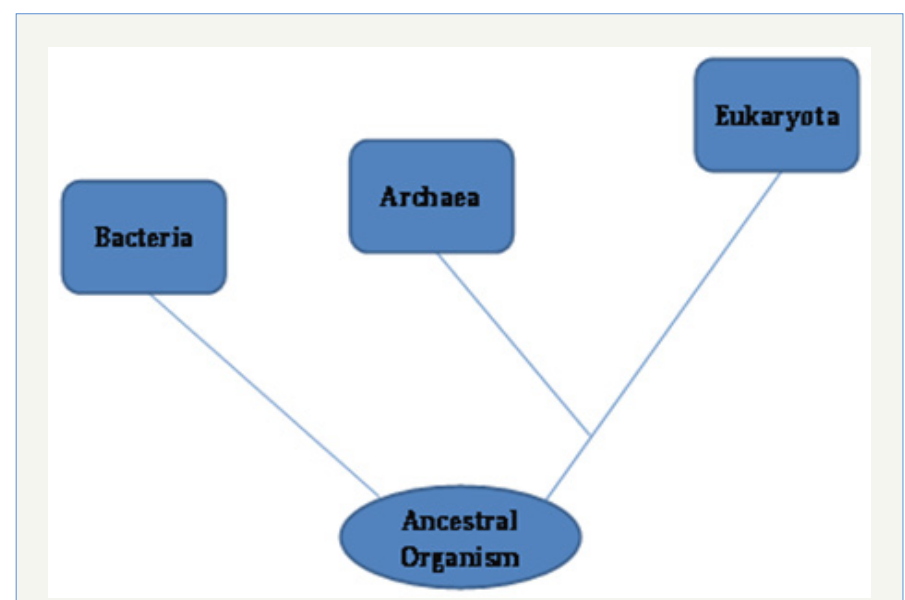

Figure 1: Simplified universal phylogenetic tree showing the evolution of the three major domains from a common ancestral life form [4].

Archaea are newly emerged domain of single-celled organisms that belong to prokaryotes. It was not until 1977 where Carl Woese and George E Fox classified this group of microorganisms separately in phylogenetic tree based on the sequencing of rRNA gene technique and not under bacteria as was thought before [1]. Archaeal microorganisms share some properties between both eukarya and bacteria. For instance, they have circular chromosome like bacteria but translation and transcription process are similar to that of eukarya [2]. However, Archaea domain is more closely related to eukaryota than bacteria as could be illustrated in (Figure 1) [3]. However, Archaea and bacteria are both similar in being free of membrane bound organelles in addition to the lack of true nucleus (membrane-bound nucleus) in contrast to the eukarya [4].

Since Archaea lineage is considered a recent discovery, little is known about it. Archaea are widely distributed in nature from ordinary habitat to harsh environmental conditions. However, many of them are uncultivable in conventional culture media and only molecular techniques could reveal their abundance and diversity in different environments [5]. Accordingly, it could be expected that these organisms may survive tough processing conditions of food and beverage industry and at the same time they may pass undetected using standard culture media in quality control laboratory. 


\section{Discussion}

While all efforts and intentions are diverted toward known pathogens that are problematic in the food and the beverage industry (when talking about safety and quality control), yet Archaea lack sufficient attention. So, scientific studies are still deficient in revealing many of mysteries that are related to this domain. This may include but not limited to the following:

\section{Role of Archaea in human pathogenesis}

Archaea are known for their ability to colonize and persist in different human parts such as mouth, vagina and colon [6-10]. Nevertheless, there are not any concrete data till now that could point to implication of Archaea to human pathogenesis [11]. However, some researchers have highlighted studies that may show involvement of some Archeal species (e.g. Sulfolobus solfataricus, Methanococcus jannaschii, Archaeoglobus fulgidus, Actinobacillus actinomycetemcomitans, haloarchaea and methanoarchaea) as human pathogen $[12,13]$.

\section{Interaction of Archaea with food and beverages}

Although many types of Archaea have found to produce several important organic solutes in biotechnological applications including preservatives [14], yet the biochemical interaction with food and beverage components including the effect of conventionally known preservatives is still anonymous in most cases. This area requires extensive studies as bimolecular interaction of Archaea of chemical entities may be unique from that of other microorganism's viz. bacteria and fungi. An interesting example is the effect of statins on methanogenic Archaeon Methanobrevibacter smithii and inhibits cell membrane biosynthesis [15].

\section{Adequacy of microbiological quality monitoring of Archaea}

Till now the conventional microbiological culture media and techniques are widely implemented in microbiology laboratory in microbiological quality control at many industries. Although traditional or culture-based tests are relatively inexpensive and reproducible, they are known to underestimate the total number of bacteria by up to several orders of magnitude, even with prolonged incubation times and temperature variations. It has long been documented that artificial culture media lead to only a very small fraction $(0.01-1 \%)$ of the total viable microorganism present in any given sample [16]. VBNC cells have also been shown to be antibiotic tolerant, as well as exhibiting tolerance to heavy metals, environment stress conditions and ethanol [17]. Many of Archaea cannot be detected by ordinary culture media but only it could be captured by the new molecular biology techniques such as nucleicacid-based methods [4].

\section{Potential ability of Archaea to form biofilm}

Archaea have the ability to establish biofilm as mechanism for survival. Again little is known till now on the biofilm formation by Archaea [18]. Archaea can form complex biofilm on biotic and abiotic surfaces, in normal and hard conditions and formed from mono species or mixed communities with varies architecture as an adaptive mechanism to the change of the environmental conditions [19]. It is obvious that this survival ability may pose threat for any water processing and distribution system in the manufacturing facility which may impact the final product accordingly.

\section{Survival of Archaea in harsh environmental conditions}

Many Archeal species are able to survive extreme environmental and chemical conditions. The survival is largely controlled by the cell cytoplasmic membrane [20]. This may raise question about their ability to withstand many detrimental conditions that are used during food and beverage manufacturing processing steps. An interesting study revealed the survival of Archaea (Euryacheota) along with bacteria in edible commercial salt samples that were able to withstand high salt conditions as extremely halophilic microbes and ingested [21]. Another example includes the ability of survival and gut colonization of methanogenic archaea (M. smithii) from raw and treated milk [22]. Archaea can survive extremes of $\mathrm{pH}$, salinity, temperature, pressure, radiation and many other unfavorable conditions of life [23]. The effect of chemical disinfectants and antiseptics is still questionable.

\section{Conclusion}

The human knowledge about microorganisms in domain Archaea is still in its infancy. Accordingly, no definitive roles about its adverse effects on human or consumable food materials have been established till now on solid scientific background. Hence, extensive researches should be conducted on these microorganisms to draw logical conclusion about their impact rather than ignoring them in order to avoid any possible futuristic harm or damage to human health or even life. After the above mentioned obstacles that represent some of the challenges, the industry engines should not just move on and ignore the presence of Archaea in any of our consumable and ingestible products before extensive scientific research could judge their effect and safety on our quality of life.

\section{Acknowledgement}

N/A

\section{Conflict of Interest}

None to declare.

\section{References}

1. Woese C, Fox G (1977) Phylogenetic structure of the prokaryotic domain: The primary kingdoms. Proc Natl Acad Sci U S A 74(11): 5088-5090.

2. Willey JM, Sherwood LM, Woolverton CJ (2008) Microbiology. ( $7^{\text {th }}$ edn), McGra-Hill, New York, USA, pp. 474-475.

3. Madigan M, Martinko J, Brock T (2006) Brock biology of microorganisms. Upper Saddle River, Pearson/Prentice Hall, New Jersey, USA.

4. Clontz L (2009) Microbial limit and bioburden tests. (2 $\left.{ }^{\text {nd }} e d n\right)$, CRC Press, Boca Raton, Florida, USA.

5. Chaban B, Ng S, Jarrell K (2006) Archaeal habitats-from the extreme to the ordinary. Can J Microbiol 52(2): 73-116.

6. Miller TL, Wolin MJ, De Macario EC, Macario AJ (1982) Isolation 
of Methanobrevibacter smithii from human feces. Appl Environ Microbiol 43(1): 227-232.

7. Bonelo G, Ventosa A, Megás M, Ruiz-Berraquero F (1984) The sensitivity of halobacteria to antibiotics. FEMS Microbiology letters 21(3): 341-345.

8. Belay N, Johnson R, Rajagopal BS, De Macario EC, Daniels L, et al. (1988) Methanogenic bacteria from human dental plaque. Appl Environ Microbiol 54(2): 600-603.

9. Belay N, Mukhopadhyay B, De Macario EC, Galask R, Daniels L, et al. (1990) Methanogenic bacteria in human vaginal samples. J clin Microbiol 28(7): 1666-1668.

10. Kulik EM, Sandmeier H, Hinni K, Meyer J (2001) Identification of archaeal rDNA from Subgingival dental plaque by PCR amplification and sequence analysis. FEMS Microbiol Lett 196(2): 129-133.

11. Eckburg P, Lepp P, Relman D (2003) Archaea and their potential role in human disease. Infect Immun 71(2): 591-596.

12. Cavicchioli R, Curmi P, Saunders N, Thomas T (2003) Pathogenic archaea: do they exist? Bioessays 25(11): 1119-1128.

13. Eckburg P, Lepp P, Relman D (2003) Archaea and their potential role in human disease. Infect Immun 71(2): 591-596.

14. Lentzen, G, Schwarz, T (2006) Extremolytes: natural compounds from extremophiles for versatile applications. Appl Microbiol Biotechnol 72(4): 623-634.

15. Gottlieb K, Wacher V, Sliman J, Pimentel M (2015) Review article: inhibition of methanogenic archaea by statins as a targeted management strategy for constipation and related disorders. Aliment Pharmacol Ther 43(2): 197-212.

16. Watkins J, Jian X (1997) Cultural methods of detection for microorganisms: recent advances and successes. The microbiological quality of water, Ambleside, England, UK.

17. Nowakowska J, Oliver JD (2013) Resistance to environmental stresses by Vibrio vulnificus in the viable but nonculturable state. FEMS Microbiol Ecology 84(1): 213-222.

18. Orell A, Fröls S, Albers S (2013) Archaeal biofilms: The great unexplored. Annu Rev Microbiol 67(1): 337-354.

19. Fröls S (2013) Archaeal biofilms: widespread and complex. Biochem Soc Trans 41(1): 393-398.

20. Konings WN, Albers SV, Koning S, Driessen A J (2002) The cell membrane plays a crucial role in survival of bacteria and archaea in extreme environments. Antonie Van Leeuwenhoek 81(1-4): 61-72.

21. Gibtan A, Park K, Woo M, Shin J, Lee D, Sohn J, et al. (2017) Diversity of extremely halophilic archaeal and bacterial communities from commercial salts. Front Microbiol 8: 799.

22. Van de Pol J, Van Best N, Mbakwa C, Thijs C, Savelkoul P, et al. (2017) Gut colonization by methanogenic archaea is associated with organic dairy consumption in children. Front Microbiol 8: 355.

23. Rampelotto P (2013) Extremophiles and extreme environments. Life 3(3): 482-485.

Your subsequent submission with Crimson Publishers will attain the below benefits

Creative Commons Attribution 4.0

International License

For possible submissions click Here

Submit Article
- High-level peer review and editorial services

- Freely accessible online immediately upon publication

- Authors retain the copyright to their work

- Licensing it under a Creative Commons license

- Visibility through different online platforms

- Global attainment for your research

- Article availability in different formats (Pdf, E-pub, Full Text)

- Endless customer service

- Reasonable Membership services

- Reprints availability upon request

- One step article tracking system 